\title{
CONHECIMENTOS E TÉCNICAS TRADICIONAIS NA EXPLORAÇÃO DE RECURSOS DOS MANGUEZAIS DA ZONA COSTEIRA DA AMAZÔNIA
}

\author{
Melgris Jose Becerra Ruiz \\ Universidade Federal do Pará (UFPA) \\ Instituto de Geociências, Pós-Graduação em Ciências Ambientais, Belém, PA, Brasil \\ jose.becerra.ruiz@gmail.com \\ Stephanie Jael Negrão de Freitas \\ Universidade Federal do Pará (UFPA) \\ Instituto de Geociências, Pós-Graduação em Ciências Ambientais, Belém, PA, Brasil \\ negro.stephanie@gmail.com \\ Paulo Amador Tavares \\ Universidade Federal do Pará (UFPA) \\ Instituto de Geociências, Pós-Graduação em Ciências Ambientais, Belém, PA, Brasil \\ atavares.paulo@gmail.com \\ Marcia Aparecida da Silva Pimentel \\ Universidade Federal do Pará (UFPA) \\ Instituto de Geociências, Pós-Graduação em Ciências Ambientais, Belém, PA, Brasil \\ marciapimentel1989@gmail.com
}

\begin{abstract}
RESUMO
Os manguezais são considerados áreas sob pressão antrópica pelo constante aumento da exploração de seus recursos, desmatamento e avanço da urbanização. Essa pesquisa teve por objetivo investigar a mobilização social como forma de construção sustentável do território. Assim, realizou-se um estudo de caso utilizando dados secundários e informações coletadas junto às comunidades. Buscando defender os recursos naturais, os moradores uniram-se formando um conselho para a criação da Reserva Extrativista (RESEX) de São João da Ponta. Os pescadores locais têm até 21 artes de pesca para captura de caranguejo. Esse conhecimento permitiu que eles adaptassem artes menos invasivas e mais sustentáveis ao habitat dos caranguejos. Os dados de mudança de uso e cobertura da Terra mostram que o mangue permaneceu inalterado na região e em 2018 representava $16,67 \%$ de toda a vegetação existente no município. A formação de pastagens não apresenta bons resultados, de tal forma que a pecuária no município, além de produzir impactos, não está sendo implantada de maneira produtiva. Ao desenvolver este estudo pôde-se perceber que as soluções para problemas socioambientais nessa região devem surgir a partir da integração do conhecimento técnico com o conhecimento local sobre o território, sendo uma abordagem recomendada para projetos futuros.
\end{abstract}

Palavras-chave: Mudança de Uso e Cobertura da Terra. Comunidades Extrativistas Tradicionais. Saberes Locais.

\section{TRADITIONAL KNOWLEDGE AND TECHNIQUES IN THE EXPLORATION OF MANGROVE RESOURCES IN THE COASTAL ZONE OF THE AMAZON}

\begin{abstract}
Mangroves are considered areas under anthropic pressure due to the constant increase in the exploitation of their natural resources, deforestation, and the urbanisation. This research aimed to investigate social mobilisation as a form of sustainable construction of the territory. Hence, a case study was carried out, using secondary data and information collected from the communities Seeking to defend the natural resources, the residents of the Municipality of São João da Ponta, formed a council to create an Extractive Reserve (RESEX) in the region. The local fisheries utilise over 21 fishing techniques to capture crabs. This knowledge allowed them to adopt less invasive and more sustainable methods to preserve the crabs' habitat. Data on land-use change and coverage show that the mangrove remained unchanged in the region and, in 2018 represented $16.67 \%$ of all vegetation in the municipality. Thus, the formation of pastures does not show good results, once that livestock in the municipality produces environmental impacts and is not being implemented
\end{abstract}


productively. Therefore, it was possible to comprehend that the solutions to socioenvironmental problems in this region must arise from the integration of technical knowledge with local knowledge about the territory, being a recommended approach for future projects.

Keywords: Land Use Change and Land Coverage. Traditional Extractive Communities. Local Knowledge.

\section{INTRODUÇÃO}

O território brasileiro detém $13.400 \mathrm{~km}^{2}$ de áreas de mangue em todo o seu litoral, correspondendo a 7,4\% da área ocupada por esse ecossistema em todo o planeta (SPALDING; BLASCO; FIELD, 1997). No estado do Pará, os manguezais formam uma faixa com cerca de $300 \mathrm{~km}$ de extensão com uma área total estimada em de $2.176,78 \mathrm{~km}^{2}$ (SOUZA FILHO, 2005).

Os manguezais são considerados áreas sob pressão antrópica devido ao constante aumento da exploração de seus recursos, ao desmatamento e à urbanização, tendo um papel fundamental nos esforços para a mitigação das mudanças climáticas, podendo absorver enormes quantidades de carbono atmosférico e servindo como barreiras aos eventos climáticos (BECERRA et al., 2020). No estado do Pará, os manguezais estão concentrados na região Nordeste, abrigando um dos maiores conjuntos de manguezais do Brasil, a maioria deles compostos por restingas, praias e dunas, nas margens das baías e dos estuários. A extensão dos mesmos é favorecida por um clima tropical úmido, com curto período seco, ventos regulares, calor constante, ausência de tempestades e nenhuma ou moderada deficiência hídrica (PROST; RABELO, 1996). Nessa região, a formação de UCs, do tipo RESEX, foi marcada pela luta e mobilização social para preservação dos modos de vida tradicionais (PIMENTEL, 2019; TEISSERENC, 2016b).

O Sistema Nacional de Unidades de Conservação (SNUC), instituído pela Lei $n^{\circ} 9.985$ de 18 de julho de 2000 (BRASIL, 2000), postula sobre a criação, implantação e gestão das UCs no Brasil, o SNUC garante ampla participação das comunidades local na elaboração, atualização e implementação do Plano de Manejo das RESEX e das Reservas de Desenvolvimento Sustentável (MENDONÇA; TALBOT, 2014). Nesse contexto, a criação de Unidades de Conservação (UCs) aparece como uma estratégia que visa a minimizar este impacto (MENEZES; MELIHG, 2009). Dentre essas UCs, destacam-se Reservas Extrativistas (RESEX), as quais visam proteger os meios de vida e a cultura de populações tradicionais, além de assegurar o uso sustentável dos recursos naturais (BRASIL, 2000).

A participação da sociedade na tomada de decisões públicas abre caminhos para novas ideias e soluções para a consolidação de cidadania e democracia. Quando se discute a respeito de participação social, trata-se de uma forma de contribuição na vida pública que objetiva o melhoramento e abertura da gestão à participação da sociedade no fomento de políticas públicas fortalecedoras que beneficiam as populações, apoiando o desenvolvimento sustentável, a democracia mais participativa e direta, que está relacionada com a garantia de envolvimento efetivo das pessoas nas decisões políticas que lhes afetam e alteram seu cotidiano, sobretudo no sentido das populações mais pobres e excluídas que vivem mais diretamente os efeitos das desigualdades sociais. Populações essas que pouco são escutadas e validadas nas decisões políticas (JACOBI; XAVIER; MISATO, 2013).

Os membros de comunidades devem relacionar-se em ações e discussões, compartilhando informações, aprendendo em mutualidade com criação de um arcabouço coparticipado de recursos: experiências, saberes, modos de lidar com problemas e com a natureza. Trata-se de uma prática compartilhada e de aprendizado social com ações que gerem: a) a ampliação do número de indivíduos no exercício desse conhecimento, e b) a comunicação entre essas pessoas, de modo a potencializar interações que impliquem no melhoramento do território (JACOBI, 2012).

Nessa perspectiva, essa pesquisa tem por objetivo investigar a mobilização social como forma de construção sustentável do território e de exploração dos recursos naturais na RESEX de São João da Ponta. Assim esse trabalho inicia-se com a contextualização do território, onde são apresentadas as formas de mobilização social responsáveis pela criação da RESEX de São João da Ponta. Em sequência é apresentada uma análise das principais formas de conversão da paisagem natural nesse território para identificar as motivações de conversão da cobertura vegetal e a produtividade dessas áreas. E, por fim, é apresentado a forma de construção de conhecimento das comunidades extrativistas tradicionais no município, com foco na pesca do caranguejo, baseando-se em dados da literatura científica da região e em informações adquiridas durante visitas técnicas na RESEX. 


\section{MATERIAIS E MÉTODOS}

\section{Área de Estudo}

O presente estudo foi desenvolvido na RESEX de São João da Ponta, localizada no município homônimo na mesorregião do salgado, no Nordeste Paraense (Figura 1). Essa RESEX abrange uma área de $3.203,24$ ha de manguezal onde habitam aproximadamente 600 famílias, divididas em 18 comunidades organizadas em cinco polos (LIMA; POZZOBON, 2005; TELES; PIMENTEL, 2018).

Figura 1 - Mapa de localização da RESEX São João da Ponta e das comunidades polos.

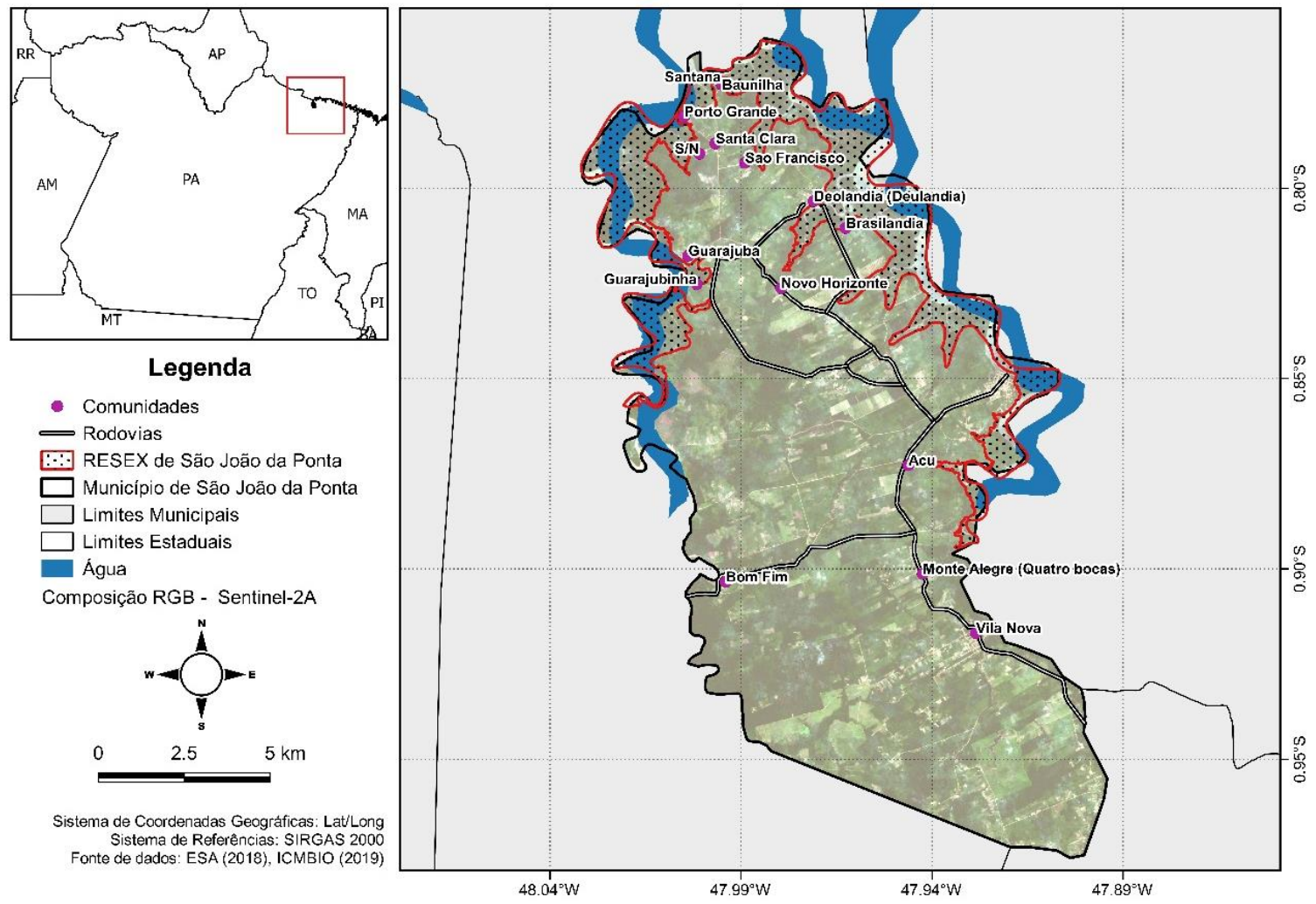

Fonte - AUTORES (2020).

\section{Delineamento do Estudo}

Para conduzir essa investigação, empregou-se uma pesquisa da natureza aplicada, com o desenvolvimento de um método dedutivo, utilizando-se a técnica de pesquisa bibliográfica e aplicação de estudo de caso, tratando-se de uma pesquisa exploratória e descritiva (PRODANOV; FREITAS, 2013).

\section{Coleta e Análise de Dados}

A pesquisa bibliográfica realizada nessa pesquisa foi baseada em artigos publicados em revistas científicas indexadas. Essas informações foram utilizadas para a contextualização dos dados gerados e para a discussão realizada em cima dos dados produzidos para a presente pesquisa científica.

Para a análise de uso e cobertura da terra, foram utilizados dados do projeto Mapbiomas coleção 4.0 (MAPBIOMAS, 2019), dos quais foram extraídas informações sobre cobertura florestal (vegetação primária e secundária), área de mangue, pastagem e infraestrutura urbana, para os anos de 1988, 1998, 2008 e 2018. Esses dados foram contrastados com as áreas desmatadas identificados pelo sistema PRODES de monitoramento de desmatamento na Amazônia brasileira (INPE, 2018) para o ano de 2018, para estimativa das áreas de vegetação primária e secundária no município de São João da Ponta. Dados oficiais da Secretaria de Estado de Desenvolvimento Agropecuário e da Pesca (SEDAP, 2018), sobre 
quantidade de rebanho bovino do município de São João da Ponta foram obtidos para levantamento da produtividade obtida com a área de pasto no território.

Por fim, informações locais sobre as comunidades habitantes na RESEX de São João da Ponta foram obtidas através de visitas técnicas. Nessas atividades, além do contato físico com o território analisado nessa pesquisa, houve a apresentação das atividades de manejo sustentável do território que são realizadas dentro da RESEX. Dentre as atividades, destacou-se principalmente a pesca do caranguejo, a qual será aprofundada na última sessão dos Resultados e Discussão.

\section{RESULTADOS E DISCUSSÃO}

\section{Contextualização do Território}

A construção do território no município de São João da Ponta teve grande participação das comunidades locais. Originalmente, essa área pertencia ao município de São Caetano de Odivelas, e para que ocorresse o processo de emancipação de São João da Ponta em 1995, diversos conflitos foram travados, de tal modo que foi somente com a união da sociedade civil que São João da Ponta se tornou um município autônomo (RODRIGUES, 2013).

Nas áreas de manguezais do município, principalmente, a população utiliza o saber ambiental para sua subsistência e manutenção da biodiversidade, devido ao fato de, no passado, a economia estar baseada na extração da malva, casca de mangue, maniva, arroz entre outras culturas de subsistência (RODRIGUES; SANTOS; PIMENTEL, 2016; TELES; PIMENTEL, 2018). Deste modo, e por causa da preservação desse saber tradicional, os moradores locais são os principais defensores dos recursos naturais locais. Tal defesa é notada no processo de criação da RESEX, onde os habitantes se uniram formando um conselho local para a criação da RESEX, que foi instituída por meio do decreto $\mathrm{S} / \mathrm{N}$ de 13 de dezembro de 2002, porém ainda não possui Plano de Manejo (TEISSERENC; SANT'ANA JÚNIOR; ESTERCI, 2016; TEISSERENC, 2016a).

Esse território apresenta pressões ambientais relacionadas à exploração dos recursos naturais, que afetam diretamente o ecossistema de manguezais e, consequentemente, o habitat dos crustáceos. Por esse motivo, toda a vez que o ambiente natural é modificado, há um aumento proporcional na quantidade de trabalho a ser desenvolvido pelas comunidades para captura dos crustáceos, causando um impacto direto na economia local, motivando as pessoas a procurarem ações para proteger, manter e gerenciar esse território de maneira mais sustentável (MOURA-FÉ et al., 2015). Em consequência, os moradores locais criam mecanismos organizacionais, permitindo a união dos líderes comunitários que trabalham no ecossistema de manguezais, reconectando a necessidade de proteção para a sustentabilidade do território.

Essa organização baseia-se no conhecimento local/étnico/tradicional que foi transmitido de geração em geração. De um modo geral, os residentes têm conhecimentos de experimentação e observação, além de raciocínio, especulação e intuição próprios (CUNHA; ALMEIDA, 2001). A compreensão holística dos processos comunitários pode ser entendida em suas múltiplas dimensões: simbólica, legal e social (DA SILVA, 2008). Essas dimensões são desenvolvidas no espaço geográfico da comunidade, onde os grupos encontram suas condições de sobrevivência.

Assim, percebe-se a importância das populações tradicionais no papel de conservação da natureza e gestão do território, sendo que a relação ser humano/natureza possui extrema importância no ordenamento e melhorias de políticas públicas. Ao passo que o tema biodiversidade começa a ser desenvolvido tendo espaço em outros âmbitos das ciências, o saber tradicional passa a ser reconhecido e torna-se imprescindível (FERREIRA; PIMENTEL; BARROS, 2016). Nesse sentido, nota-se a importância de explorar as mudanças nas formas de uso e ocupação da terra no município de São João da Ponta, de tal forma a entender as ações e impasses que os atores do território tiveram para construção e desenvolvimento da RESEX homônima.

\section{As Formas de Uso e Ocupação da Terra e a Dinâmica Social no Território}

Como apresentado, a criação da RESEX de São João da Ponta, em 2002, foi fortemente vinculada a mobilização social de grupos e entidades, os quais desempenham, dentro do conselho deliberativo e até mesmo na gestão municipal, forte influência na tomada de decisão desde 2008. No município de São João da Ponta como um todo, ocorreram grandes mudanças econômicas, sociais e políticas desde a

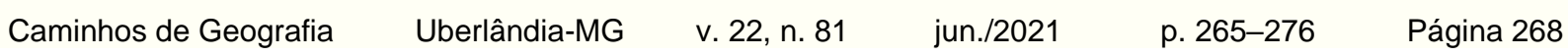


criação da RESEX, isso porque grande parte dos habitantes ( $60 \%$ do eleitorado) do município são usuários da área extrativista, dando grande poder na gestão municipal para pessoas vinculadas ao conselho deliberativo da RESEX (TEISSERENC, 2016b).

Entre os anos de 1998 e 2008 ocorreu a maior perda de cobertura florestal nas três décadas analisadas (Figura 2). Foi durante esse período que a RESEX de São João da Ponta foi criada e fortalecida. Essa UC tem como um de seus objetivos assegurar o uso sustentável dos recursos naturais na região, preservando - Manguezal existente na região. Os dados de mudança de uso e cobertura da Terra mostram que o mangue permaneceu inalterado na região e em 2018 representava $16,67 \%$ de toda a vegetação existente na área (em 1988, essa contribuição era de 13,88\%).

Figura 2 - Mapas demonstrando a mudança de uso e cobertura da Terra no Município de São João da Ponta entre os anos de 1988 e 2018.

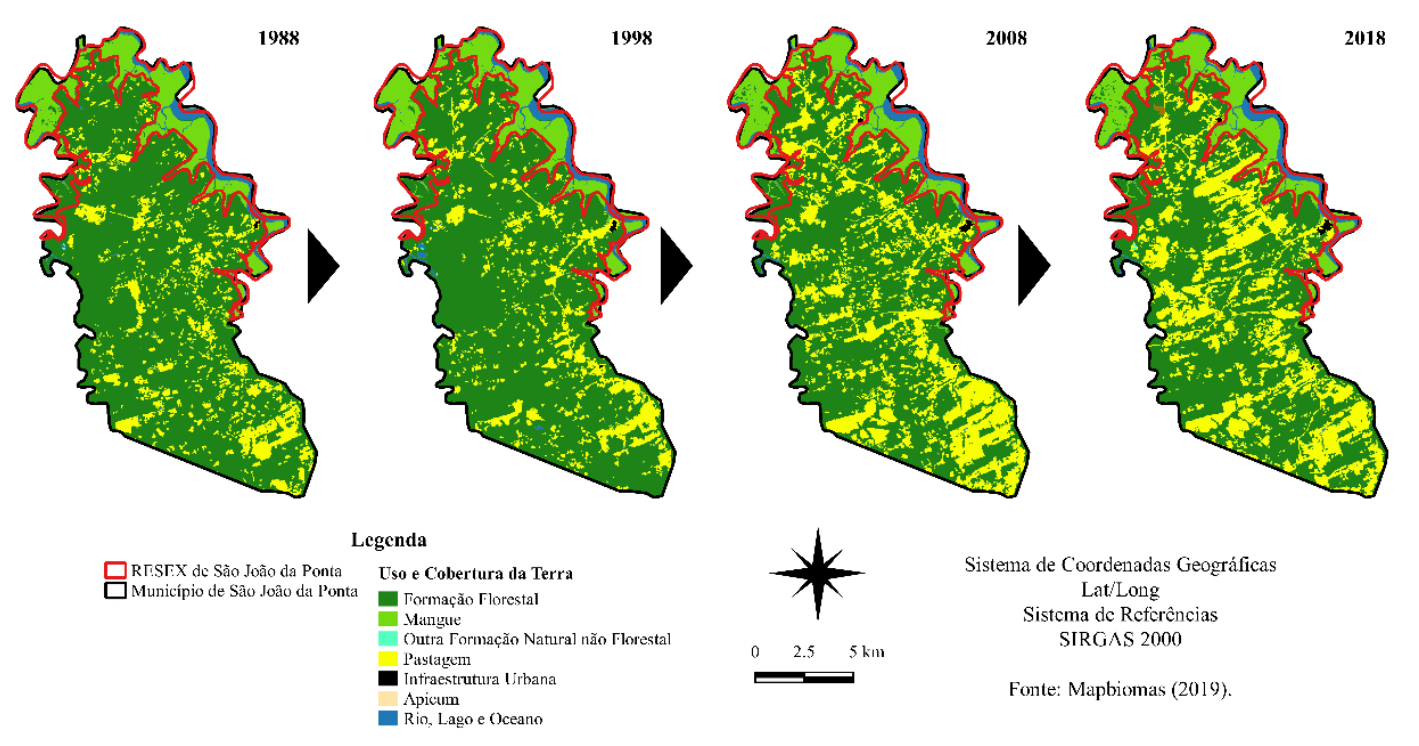

Fonte - MAPBIOMAS (2019).

A análise visual da Figura 2 mostra uma significante perda de camada florestal, a qual está sendo convertida principalmente em pasto, enquanto a área de mangue permanece praticamente inalterada nos mapas apresentados. Os valores de área de conversão de cobertura da Terra são apresentados na Tabela 1. Destaca-se que os produtos do Mapbiomas não distinguem vegetação primária de secundária, assim, ao excluir a área desmatada do município até (11.020 ha; (INPE, 2018), obtêm-se uma estimativa do total de área de vegetação primária e secundária no município, 5.587,70 ha e 5.816,10 ha, respectivamente.

Tabela 1 - Dados de mudança de uso e cobertura da Terra no município de São João da Ponta.

\begin{tabular}{ccccc}
\hline \multirow{2}{*}{ Tipo de Uso e Cobertura da Terra } & \multicolumn{4}{c}{ Área em hectares } \\
\cline { 2 - 5 } & $\mathbf{1 9 8 8}$ & $\mathbf{1 9 9 8}$ & $\mathbf{2 0 0 8}$ & $\mathbf{2 0 1 8}$ \\
\hline Formação Florestal & $14.258,52$ & $14.210,28$ & $11.795,13$ & $11.403,81$ \\
Mangue & $2.298,24$ & $2.369,97$ & $2.313,00$ & $2.281,95$ \\
Pastagem & $2.528,82$ & $2.446,29$ & $4.913,91$ & $5.203,89$ \\
Infraestrutura Urbana & 9,00 & 16,74 & 35,10 & 39,87 \\
\hline & Fonte - MAPBIOMAS (2019).
\end{tabular}


A formação de pastagens, ainda que o principal causador da mudança de uso da terra no município de São João da Ponta (crescendo de $13,2 \%$ para $25,5 \%$ de representatividade no município), não apresenta bons resultados quando comparados com a produção de cabeças de gado, o que corresponde a aproximadamente 0,33 cabeças de gado por hectare de pasto. De acordo com dados oficiais do Estado do Pará (SEDAP, 2018), o rebanho bovino no município cresceu apenas $8,8 \%$ entre os anos de 2000 e 2016 (de 1.500 para 1.632 cabeças de gado). Para o ano de 2016, esse valor representou apenas $0,72 \%$ da produção da mesorregião do Guamá, onde esse município está localizado no Estado do Pará.

Por essas razões, infere-se que a pecuária no município, além de produzir os impactos ambientais inerentes a esse tipo de atividade, não está sendo implantada de maneira produtiva. Para os autores (VERBURG et al., 2011), a baixa produtividade na Amazônia é um dos principais causadores do aumento anual do desmatamento. De maneira similar, (VIEIRA; SANTOS JÚNIOR; TOLEDO, 2014) propõe que o modelo socioambiental de desenvolvimento nessas regiões seja baseado nas vocações locais e na implantação de mais de uma cultura de plantação, formando-se produções agrossilvipastoris, nas quais os produtores rurais têm a possibilidade de produzir diversos tipos de culturas em sinergia com a pecuária, garantindo a sustentabilidade ambiental e econômica da propriedade, além da segurança alimentar da população rural.

Entretanto, pensar o desenvolvimento do território na Amazônia, ainda que rico em possibilidades (NOBRE et al., 2016), é desafiante devido as diferentes realidades locais, com a falta de assistência técnica e acesso às instituições de fomento para pequenos e médios agricultores (BRAGA; FUTEMMA, 2015). Desta forma, é fundamental pensar em formas de desenvolvimento que incluam a participação social, tal como as RESEX permitem, favorecendo as mudanças no poder local (COSTA et al., 2018).

Para o pesquisador Pierre Teisserenc (TEISSERENC, 2011) o modelo de desenvolvimento social e ambiental existente em RESEX tende a ser ideal para a manutenção e reconhecimento saberes das comunidades tradicionais. Como visto na atividade de campo, os conhecimentos tradicionais são incorporados nas atividades dos usuários da RESEX de São João da Ponta, de tal modo que a adaptabilidade dessas comunidades seja feita respeitando tanto os conhecimentos científicos como os das populações residentes da área. Assim, a RESEX de São João da Ponta, como é mencionada por Porto-Gonçalves (2015), é uma forma de resistência das comunidades tradicionais locais as formas de expansão capitalista desenvolvidas na Amazônia brasileira.

Deste modo, faz-se necessário investigar as formas de uso sustentável dos recursos naturais existentes no município de São João da Ponta, o qual tem sua economia baseada na pesca e agricultura familiar (RODRIGUES, 2013). A pesca artesanal de crustáceos é a que fornece maiores retornos financeiros para as populações tradicionais, de acordo com estudos sobre o manejo e a sustentabilidade econômica em áreas de manguezais brasileiros. Dentre os crustáceos, o caranguejo-uçá (Ucides cordatus), representa um dos mais importantes recursos das regiões estuarinas da costa brasileira (LIMA; MOCHEL; CASTRO, 2010), sendo que na RESEX de São João da Ponta diversas são as formas passadas de geração para geração para pesca e manejo desse recurso natural.

\section{Uso Local e Coletivo do Saber na Captura de Caranguejos}

Extrair caranguejos não é uma tarefa fácil, requer experiência e mão de obra qualificada. Identificar os locais onde eles vivem, conhecer a sazonalidade da desova, diferenciar machos das fêmeas e, principalmente, manter e administrar os locais onde os caranguejos vivem. Isso se traduz em conhecimento local que aponta para uma boa gestão do território. O conhecimento coletivo local está associado à troca de informações, onde as comunidades falam sobre os locais mais importantes para captura, quais são os adequados e quais não são, esses conhecimentos têm um alto valor social, porque 
é lá que a transmissão do conhecimento passa de pais para filhos, de geração em geração, entre comunidades e entre homens e mulheres (PIMENTEL; RIBEIRO, 2016).

O conhecimento local é uma peça fundamental para a gestão coletiva do território articulado com organizações de base e órgãos governamentais (FERREIRA, 2017). Foi a partir da articulação que as comunidades locais de São João da Ponta decidiram desenvolver seus próprios mecanismos de sustentabilidade do ambiente natural, um processo reflexivo para manter os recursos que, além da manutenção dos recursos naturais, sustentam a economia local.

$\mathrm{Na}$ narrativa desses coletores de caranguejo, pode-se perceber que, conhecendo as mudanças no nível das marés e no movimento das ondas, os coletores podem interpretar os sinais de que será uma boa época de captura ou não do crustáceo. Por outro lado, o entendimento da sazonalidade e dos padrões de precipitação pode levar à escolha de uma técnica de colheita mais apropriada, o que permitirá manter o equilíbrio da coleta e a sustentabilidade do caranguejo e seu habitat.

Os caranguejeiros comentam que as fases da lua desempenha um papel importante nos manguezais e, o conhecimento sobre o comportamento desse ambiente natural, indica aos coletores quais devem ser os dias de início das ações, sendo um ou dois dias antes a lua cheia ou nova (DIELE; KOCH, 2010; NORDI, 1994). Essas práticas na alternância das fases da lua são baseadas no conhecimento tradicional. Os coletores têm uma medida de precaução, frente as fases da lua, a captura de caranguejos é proibida por seis dias após a lua cheia ou seis dias após a lua nova (PASSOS, 2015).

O conhecimento biológico e ecológico dos manguezais mostra que a vida dos crustáceos tem uma forte atração com os ciclos da lua, que por sua vez exerce força nas correntes marinhas e tangencialmente na vida na Terra, as fases lunares afetam movimento dos mares (ALVES; NISHIDA, 2003). Por outra lado, as comunidades que habitam perto dos manguezais e dependem de seus recursos, apresentam um bom conhecimento dos componentes biótico e abióticos desse ecossistema, sabendo os períodos adequados para realizar as atividades de captura dos caranguejos.

Os coletores locais, declaram que podem reconhecer até 21 artes de pesca para captura do caranguejo, onde consideram diferentes variáveis (sexo, tamanho, sazonalidade, entre outras). Esse conhecimento Ihes permitiu gerenciar equipamentos de pesca sustentáveis, conseguindo assim manter o habitat dos caranguejos. De acordo com os coletores, entre os meses de março e abril, esses crustáceos iniciam uma estação de engorda, estendendo-se até os meses de setembro e outubro (SOUTO, 2007). Durante esse processo, o mar e o manguezal servem como local de desova. Após o acasalamento, as fêmeas cavam e depositam seus ovos ali, esse movimento entre os galhos do manguezal e termina no mar onde as ovas são liberadas, fornecendo condições para os estágios do ovo, larva e pós-larva (CAVALCANTE et al., 2011).

Os coletores de caranguejo que moram próximo ao RESEX São João da Ponta, são considerados usuários naturais da extração de caranguejos, sendo esse o principal recurso econômico para geração de renda e segurança alimentar no local (ICMBIO, 2010). Eles têm um profundo conhecimento dos caranguejos, conhecem detalhes como período de reprodução, ecdise (troca periódica de carapaça), determinação sexual e as características diferenciais dos furos que cavam, preferencialmente coletando machos. (CAVALCANTE et al., 2011; SOUTO, 2007).

Entre as técnicas utilizadas com frequência, foram citadas: o laço, a tapa, o braço e o gancho. Os coletores de caranguejo relatam que podem usar a técnica do laço ao longo do ano, mas principalmente no ciclo de menos chuvas (verão), porque lá o substrato é mais firme, para a estação mais chuvosa (inverno) eles usam a técnica de tapagem ou tapa, porque o substrato é menos firme (RIVERA, 2015). O Quadro 1 destaca as vantagens e desvantagens na utilização das duas principais técnicas descritas por Rivera (2015), o Laço e a Tapa. 
Quadro 1 - Comparativo das Vantagem e Desvantagens das principais técnicas para coleta de caranguejo.

\begin{tabular}{|c|c|c|c|}
\hline Técnicas & Atividade & Vantagem & Desvantagens \\
\hline Laço & $\begin{array}{l}\text { É a construção de uma armadilha que é } \\
\text { elaborado a partir de uma planta (vara de rego, } \\
\text { vassoura Comolia villosa, varinha verde, cumaté } \\
\text { Myrcia fallax), a madeira é extraída para } \\
\text { construir as conexões dos laços. } \\
\text { Este é um processo longo que requer medir os } \\
\text { comprimentos, cortá-los e afiar as pontas que } \\
\text { serão inseridas no chão. São amarrados de } \\
\text { uma extremidade à outra com um nó deslizante. } \\
\text { Uma vez localizado o local, o caranguejeiro } \\
\text { coloca o laço e monta três pontos perto da } \\
\text { abertura, que, por sua experiência, sabe } \\
\text { distinguir entre machos e fêmeas. } \\
\text { A distinção entre machos e fêmeas (as quais } \\
\text { não são coletadas) é feita através das fezes } \\
\text { encontradas que variam em tamanho e } \\
\text { coloração (ALVES; NISHIDA, 2003; SOUTO; } \\
\text { PACHECO, 2012). }\end{array}$ & $\begin{array}{l}\text { O caranguejo não é } \\
\text { forçado a se retirar do } \\
\text { buraco. } \\
\text { Permitem a distinção } \\
\text { entre machos e } \\
\text { fêmeas. } \\
\text { As fêmeas deixam } \\
\text { uma trilha estreita e } \\
\text { rasa. } \\
\text { Os machos deixam } \\
\text { uma trilha grossa e } \\
\text { com escavações no } \\
\text { chão, sendo } \\
\text { observadas também as } \\
\text { cerdas nas que são } \\
\text { mais abundantes nos } \\
\text { machos. }\end{array}$ & $\begin{array}{l}\text { A técnica é mais viáve } \\
\text { de ser utilizada } \\
\text { principalmente no } \\
\text { verão. }\end{array}$ \\
\hline Tapa & $\begin{array}{l}\text { É uma forma de trabalho com o braço para a } \\
\text { extração do caranguejo. Uma vez escolhido o } \\
\text { local de coleta, os caranguejeiros usam } \\
\text { equipamentos para proteger as mãos, braços, } \\
\text { pernas e pés. Se localiza a galeria, o coletor } \\
\text { introduz o braço, reconhecendo a direção dos } \\
\text { caminhos dentro da galeria feitos pelo } \\
\text { caranguejo, forçando o caranguejo a vir à } \\
\text { superfície. } \\
\text { Pode ser realizado em uma área de } 100 \text { a } 150 \\
\text { galerias e, após aproximadamente } 30 \text { minutos, } \\
\text { o coletor apenas passa para procurar } \\
\text { caranguejos na superfície. }\end{array}$ & $\begin{array}{l}\text { É um processo que } \\
\text { não demanda muito } \\
\text { tempo. } \\
\text { É possível reconhecer } \\
\text { as galerias feitas pelos } \\
\text { caranguejos, não } \\
\text { ocupa muito espaço. }\end{array}$ & $\begin{array}{l}\text { O emprego desta } \\
\text { técnica pode ocasionar } \\
\text { mais mortalidade para } \\
\text { os caranguejos. }\end{array}$ \\
\hline
\end{tabular}

Fonte - Autores (2020) com base em Rivera (2015).

Assim, pôde-se evidenciar que a população de pescadores de São João da Ponta desenvolveu seus próprios mecanismos de sustentabilidade ambiental para a produção de caranguejo. Essas estratégias nascem da autorreflexão da comunidade de manter os recursos naturais que sustentam a economia local. Nesta comunidade, a maior vantagem que eles têm é a disposição de respeitar os acordos de extração e colheita do caranguejo, através da conscientização coletiva e da autoavaliação permanente das técnicas de pesca utilizadas.

O conhecimento local é essencial, como forma de uso sustentável dos recursos naturais da RESEX, seu conhecimento é essencial como fonte de informações confiáveis e atualizadas sobre o estado dos recursos, o comportamento do ecossistema e mudanças nas características locais, o que ajuda a obter informações teóricas e práticas para gerenciar e conservar recursos de um ponto de vista sustentável.

\section{CONSIDERAÇÕES FINAIS}

Com o desenvolvimento dessa pesquisa pôde-se perceber que o município de São João da Ponta tem a sua economia baseada no aproveitamento dos recursos naturais, principalmente a pesca de caranguejos. Evidenciou-se também que ainda que grandes áreas sejam destinadas para a produção agropecuária, baixa é a produtividade dessas terras, tornando fundamental o conhecimento tradicional para o desenho de políticas públicas adequadas e pertinentes à exploração dos recursos dos manguezais. 
Outro fator característico da região foi a força da mobilização social, a qual foi a originadora da RESEX homônima do município. Essa organização foi também identificada no estudo teórico como arena de debate que consolidou a gestão municipal nas mãos dos habitantes e trabalhadores extrativistas da localidade. Exemplos como esse são significativos para a gestão ambiental e social sustentável do território.

A organização social dos moradores da RESEX de São João da Ponta faz um esforço significativo para proteger seu território e suas práticas de subsistência dentro de uma figura jurídica de proteção ambiental, consolidando a estratégia de participação social com muita influência no município na atualidade. Por outro lado, as artes de pesca atuais definidas entre os coletores fazem uma forma adequada para o desenvolvimento sustentável que permita garantir para o futuro a conservação dos manguezais, sendo produto da autorreflexão e avaliação permanente nas comunidades, procurando sempre mecanismos e equipamentos para pesca sustentável, garantindo renda e segurança alimentar para as comunidades.

Por fim, a construção do território e da paisagem, no município de São João da Ponta, tem grande influência humana. A parte extrativista tradicional apresenta resultados mais significativos para o município, enquanto a conversão da camada vegetal para pecuária ou agricultura não tem significativo impacto econômico e social para o município. Neste sentido, as atividades extrativistas tradicionais devem ser consideradas e integrar-se dentro das políticas públicas do município, tendo a necessidade da implantação de políticas de educação ambiental e consideração de taxa de crescimento da população.

Assim, dada a capacidade de mobilização das comunidades de São João da Ponta, é possível pensar na construção de soluções técnicas para os problemas socioambientais da região em conjunto com as comunidades, sendo essa uma abordagem que deve ser explorada em projetos futuros para a região. Algumas das soluções técnicas poderiam ser o fortalecimento da coparticipação entre população local, órgãos competentes, universidades, ONG's, a manutenção e valorização ainda mais efetiva do conhecimento tradicional; que o poder público deve levar em consideração como estratégia de conservação e manutenção dos recursos naturais providos pelos manguezais.

\section{AGRADECIMENTOS}

O presente trabalho foi realizado com apoio da Coordenação de Aperfeiçoamento de Pessoal de Nível Superior - Brasil (CAPES) - Código de Financiamento 001. Os autores também agradecem à Associação dos Usuários da RESEX de São João da Ponta pelo recebimento e compartilhamento de informações sobre a área de estudo. Os autores agradecem as contribuições dadas pelos revisores anônimos do artigo.

\section{REFERÊNCIAS}

ALVES, R. R. N.; NISHIDA, A. K. Aspectos socioeconômicos e percepção ambiental dos catadores de caranguejo-uçá Ucides cordatus cordatus (L. 1763) (Decapoda, Brachyura) do estuário do rio Mamanguape, Nordeste do Brasil. Interciencia, [S. I.], v. 28, n. 1, p. 36-43, 2003.

BECERRA, M. J. et al. Geospatiality of climate change perceptions on coastal regions: A systematic bibliometric analysis. Geography and Sustainability, set. 2020. https://doi.org/10.1016/i.geosus.2020.09.002

BRAGA, A. C. R.; FUTEMMA, C. Pluralidade da Assistência Técnica e Extensão Rural. Ruris, [S. I.], v. 9, n. 2, p. 239-268, 2015.

BRASIL. Lei no 9.985, de 18 de julho de 2000. Regulamenta o art. 225, § 10, incisos I, II, III e VII da constituição federal, institui o sistema nacional de unidades de conservação da natureza e dá outras providências.Diário Oficial da União: Brasília-DF, 2000.

CAVALCANTE, A. N.; ALMEIDA, Z. S.; PAZ, A. C.; NAHUM, V. J. I. Análise multidimensional do sistema de produção pesqueira caranguejo-uçá, Ucides cordatus, no município de Araioses, Maranhão - Brasil. Arq. Ciên. Mar, Fortaleza, [S. I.], v. 44, n. 3, p. 87-98, 2011.

COSTA, D. C.; PEREIRA, H. S.; MARCHAND, G. A. E. L.; SILVA, S. C. P. Challenges of participatory community monitoring of biodiversity in protected areas in Brazilian Amazon. Diversity, [S. I.], v. 10, n. 3, 2018. DOI: 10.3390/d10030061. https://doi.org/10.3390/d10030061 
CUNHA, M. C.; ALMEIDA, M. W. B. Populações tradicionais e conservação ambiental. In: CAPOBIANCO, J. R. et al. (org.). Biodiversidade na Amazônia brasileira: avaliação e ações prioritárias para a conservação, uso sustentável e repartição de benefícios. 1. ed. São Paulo: Instituto Socioambiental, 2001.

DA SILVA, R. O. Biodiversidade e Políticas de Conservação: o caso do Parque Estadual MonteAlegre - Pará. 2008. UNB, [S. I.], 2008.

DIELE, K.; KOCH, V. Growth and mortality of the exploited mangrove crab Ucides cordatus (Ucididae) in N-Brazil. Journal of Experimental Marine Biology and Ecology, [S. I.], v. 395, n. 1-2, p. 171180, 2010. DOI: 10.1016/j.jembe.2010.08.029. https://doi.org/10.1016/j.jembe.2010.08.029

ESA - European Space Agency. Copernicus Open Access Hub. 2018. Disponível em: https://scihub.copernicus.eu/dhus/\#/home. Acesso em: 28 set. 2020.

FERREIRA, S. da S. Entre marés e mangues: paisagens territorializadas por pescadores da Resex marinha de São João da Ponta/PA. 2017. UFPA, [S. I.], 2017.

FERREIRA, S. S.; PIMENTEL, M. A. S.; BARROS, D. M. Paisagens transversais e ordenamento territorial em áreas protegidas: análise paisagística do meio ambiente territorializado por comunidades extrativistas da Amazônia. Contribuciones a las Ciencias Sociales, [S. I.], p. 45-66, 2016.

ICMBIO - Instituto Chico Mendes de Conservação da Biodiversidade. Caracterização dos Aspectos Socioambientais e Econômicos da Reserva Extrativista de São João da Ponta e Proposta de Estudos Complementares. São João da Ponta. 2010.

Geoprocessamento. 2019. Disponível em: https://www.icmbio.gov.br/portal/geoprocessamento1. Acesso em: 28 set. 2020.

INPE - Instituto Nacional de Pesquisas Espaciais. PRODES Digital. 2018. Disponível em: http://www.dpi.inpe.br/prodesdigital/prodes.php. Acesso em: 11 out. 2018.

JACOBI, P. R. Governança ambiental, participação social e educação para a sustentabilidade. In: PHILIPPI, A.; ET AL (org.). Gestão da Natureza Pública e Sustentabilidade. São Paulo: Manole, 2012. p. 343-361.

JACOBI, P. R.; XAVIER, L. Y.; MISATO, M. T. Aprendizagem social e unidades de conservação: aprender juntos para cuidar dos recursos naturais. São Paulo: IEE/PROCAM, 2013.

LIMA, D.; POZZOBON, J. Amazônia socioambiental: sustentabilidade ecológica e diversidade social. Estudos Avançados, [S. I.], v. 19, n. 54, p. 45-76, 2005. DOI: 10.1590/S0103-40142005000200004. https://doi.org/10.1590/S0103-40142005000200004

LIMA, M. N. B.; MOCHEL, F. R.; CASTRO, A. C. L. O sistema de produção do caranguejo-uçá Ucides cordatus (Decapoda: Brachyura) (Linnaeus, 1763) na Área de Proteção Ambiental das Reentrâncias Maranhenses, Brasil. Bol. do Lab. de Hidrobiologia, [S. I.], v. 23, p. 57-64, 2010.

MAPBIOMAS. Mapbiomas Collection 4.0. 2019. Disponível em: http://mapbiomas.org/. Acesso em: 4 nov. 2019.

MENDONÇA, F.; TALBOT, V. Participação Social na Gestão de Unidades de Conservação: uma Leitura sobre a Contribuição do Instituto Chico Mendes. Biodiversidade Brasileira, [S. I.], v. 4, n. 1, p. 211-234, 2014.

MENEZES, M. P. M.; MELIHG, U. Manguezais as florestas da Amazônia Costeira. Rev. Ciência Hoje, [S. I.], v. 264, n. 44, p. 35-39, 2009. https://doi.org/10.1590/S0100-19652006000100005

MOURA-FÉ, M. M.; ALBUQUERQUE, A. G. B. M.; FREITAS, E. M. N.; BARBOSA, W. R. A Proteção do Ecossistema Manguezal pela Legislação Ambiental Brasileira. GEOgraphia, [S. I.], v. 17, n. 33, p. 126, 2015. DOI: 10.22409/GEOgraphia2015.v17i33.a13700.

NOBRE, C. A.; SAMPAIO, G.; BORMA, L. S.; CASTILLA-RUBIO, J. C.; SILVA, J. S.; CARDOSO, M. Land-use and climate change risks in the Amazon and the need of a novel sustainable development paradigm. Proceedings of the National Academy of Sciences, [S. I.], v. 113, n. 39, p. 1075910768, 2016. DOI: 10.1073/pnas.1605516113. https://doi.org/10.1073/pnas.1605516113

NORDI, N. A. A captura do caranguejo-uçá (Ucides cordatus) durante o evento reprodutivo da espécie: o ponto de vista dos caranguejeiros. Revista Nordestina de Biologia, [S. I.], v. 9, p. 41-47, 
1994.

PASSOS, P. H. D. S. Ciência ao sabor do mangue: o saber do caranguejeiro melhorando a condição de trabalho e renda. 2015. Instituto Federal de Educação, Ciência e Tecnologia do Pará, [S. l.], 2015.

PIMENTEL, M. A. S. Comunidades tradicionais em reservas extrativistas marinhas no estado do Pará: Conflitos e resistências. Ambientes, [S. I.], v. 1, n. 1, p. 191-218, 2019. https://doi.org/10.48075/amb.v111.22690

PIMENTEL, M. A. S.; RIBEIRO, W. C. Populações tradicionais e conflitos em áreas protegidas. GEOUSP: Espaço e Tempo (Online), [S. I.], v. 20, n. 2, p. 224, 2016. DOI: 10.11606/issn.21790892.geousp.2016.122692. https://doi.org/10.11606/issn.2179-0892.geousp.2016.122692

PORTO-GONÇALVES, C. Amazônia enquanto acumulação desigual de tempos: uma contribuição para a ecologia política da região. Revista crítica de ciencias sociais, [S. I.], n. 107, p. 63-90, 2015. DOI: $10.4000 /$ rccs.6018. https://doi.org/10.4000/rccs.6018

PRODANOV, C. C.; FREITAS, E. C. de. Metodologia do Trabalho Científico: Métodos e Técnicas de Pesquisa e do Trabalho Acadêmico. $2^{\mathrm{a}}$ ed. Novo Hamburgo - Brasil: Feevale, 2013. DOI: 10.1017/CBO9781107415324.004. https://doi.org/10.1017/CBO9781107415324.004

PROST, M. T. R. C.; RABELO, B. V. Variabilidade fito-espacial de manguezais litorâneos e dinâmica costeira: exemplos da Guiana Francesa, Amapá e Pará. Boletim do Museu Paraense Emilio Goeldi, [S. I.], v. 8, p. 101-121, 1996.

RIVERA, D. S. B. Conhecimento tradicional como instrumento para conservação e manejo do caranguejo uçá ucides cordatus (linnaeus, 1763) na reserva extrativista marinha de São João da Ponta - Pará. 2015. Instituto Nacional de Pesquisas na Amazônia, [S. I.], 2015.

RODRIGUES, W. L. J. Memória de São Joao da Ponta - PA a partir de narrativas orais. 1. ed. Belém: GEPPAM/UFPA, 2013.

RODRIGUES, W. L. J.; SANTOS, V. C.; PIMENTEL, M. A. S. Geotecnologias e saberes tradicionais aplicados à análise espaço-temporal. Revista ACTA Geográfica, [S. I.], p. 27-43, 2016.

SEDAP - Secretaria de Estado de Desenvolvimento Agropecuário e da Pesca. Efetivo de Rebanho Bovino 2000-2016. 2018. Disponível em: http://www.sedap.pa.gov.br/content/bovinos. Acesso em: 4 nov. 2019.

SOUTO, F. J. B. Uma abordagem etnoecológica da pesca do caranguejo, Ucides cordatus, Linnaeus, 1763 (Decapoda: Brachyura), no manguezal do Distrito de Acupe (Santo Amaro-BA). Biotemas, [S. I.], n. 20, p. 69-80, 2007. https://doi.org/10.13102/scb103

SOUTO, F. J. B.; PACHECO, R. S. Percepção morfológica de animais aquáticos pela comunidade pesqueira de Acupe, Santo Amaro, Bahia: uma abordagem etnozoológica. SITIENTIBUS série Ciências Biológicas, [S. I.], v. 11, n. 2, p. 103, 2012. DOI: 10.13102/scb103.

SOUZA FILHO, P. W. M. Costa de manguezais de macromaré da Amazônia: cenários morfológicos, mapeamento e quantificação de áreas usando dados de sensores remotos. Revista Brasileira de Geofísica, [S. I.], v. 23, n. 4, p. 427-435, 2005. DOI: 10.1590/S0102-261X2005000400006. https://doi.org/10.1590/S0102-261X2005000400006

SPALDING, M.; BLASCO, F.; FIELD, C. World Mangrove Atlas. 1. ed. Okinawa-Japão: ISME, 1997.

TEISSERENC, M. J. S. A.; SANT'ANA JÚNIOR, H. A.; ESTERCI, N. Iniciando a conversa: ações locais e dinâmicas territoriais e socioeconômicas na Amazônia brasileira. In: TEISSERENC, M. J. S. A.; SANT'ANA JÚNIOR, H. A.; ESTERCI, N. (org.). Territórios, Mobilizações e Conservação Socioambiental. São Luís-Brasil: EDUFMA, 2016.

TEISSERENC, M. J. da S. A. Politização, Ambientalização e Desenvolvimento Territorial em Reservas Extrativistas. Caderno CRH, [S. I.], v. 29, n. 77, p. 229-242, 2016. a. DOI: 10.1590/S010349792016000200003. https://doi.org/10.1590/S0103-49792016000200003

TEISSERENC, P. Reconhecimento de saberes locais em contexto de ambientalização. Novos Cadernos NAEA, $[S$. I.], v. 13, n. 2, p. 341-357, 2011 . DOI: 10.5801/ncn.v13i2.473. https://doi.org/10.5801/ncn.v13i2.473 
TEISSERENC, P. Poder local e condições de sua renovação na Amazônia. Novos Cadernos NAEA, [S. I.], v. 19, n. 1, p. 47-70, 2016. b. DOI: 10.5801/ncn.v19i1.2451. https://doi.org/10.5801/ncn.v19i1.2451

TELES, G. C.; PIMENTEL, M. A. da S. Análise de Conflitos Sócioambientais nas Reservas Extrativistas de São João da Ponta e Curuçá-PA. Geoambiente On-line, [S. I.], n. 31, 2018. DOI: 10.5216/revgeoamb.v0i31.48852. https://doi.org/10.5216/revgeoamb.v0i31.48852

VERBURG, R.; LINDOSO, D.; DEBORTOLI, N.; RODRIGUES FILHO, S. Towards a low carbon economy in the Amazon: the role of land-use policies. Sustentabilidade em Debate, [S. I.], v. 2, n. 2, p. 83-96, 2011. DOI: 10.18472/SustDeb.v2n2.2011.5820.

VIEIRA, I. C. G.; SANTOS JÚNIOR, R. A. O.; TOLEDO, P. M. Dinâmicas produtivas, transformações no uso da terra e sustentabilidade na Amazônia. In: SIFFER, N.; CARDOSO, M.; MAGALHÃES, W. de A.; LASTRIZ, H. M. M. (org.). Um Olhar Territorial para o Desenvolvimento: Amazônia. 1. ed. Rio de Janeiro: BNDES, 2014. p. 370-395.

Recebido em: 23/06/2020

Aceito para publicação em: 30/09/2020 